Farklı rezidüel kemik yüksekliğinde sinüs tabanı yükseltme operasyonu ile eşzamanlı yerleştirilen implantların sağkalımının değerlendirilmesi

\section{Evaluation of survival of implants placed simultaneously with sinus floor elevation operation at different residual bone height}

\section{Dr. Elçin Bedeloğlu}

İstanbul Aydın Üniversitesi, Diş Hekimliği Fakültesi, Ağız, Diş ve Çene Cerrahisi Anabilim Dalı

\section{Dr. Alper Bahattin Gültekin}

İstanbul Üniversitesi, Diş Hekimliği Fakültesi, Oral İmplantoloji Anabilim Dalı

Geliş tarihi: 15 Ocak 2018

Kabul tarihi: 7 Mart 2018

doi: 10.5505/yeditepe.2018.49404

\section{Yazışma adresi:}

Dr. B. Alper Gültekin

İstanbul Üniversitesi Diş Hekimliği Fakültesi,

Oral İmplantoloji A.D. Fatih-ìstanbul

Tel: 05326757236

E-posta: alpergultekin@hotmail.com
ÖZET

Amaç: Dişlerin kaybedilmesi sonrası alveolar kemikte rezorpsiyon meydana gelmektedir. Posterior maksillada yetersiz kemik yüksekliği durumunda, implant yerleştirilmesi için sinüs tabanı operasyonu uzun yıllardır başarılı bir şekilde uygulanmaktadır. Bu çalışmanın amacı posterior maksillada sinüs tabanı altında kemik yüksekliğinin implant yerleştirilmesi için yetersiz olduğu durumlarda, sinüs tabanı yükseltme operasyonu ile eşzamanlı yerleştirilen implantların başarısını değerlendirmektir.

Gereç ve Yöntem: Bu retrospektif planlanan çalışmaya sistemik olarak sağlıklı ve posterior maksillada dental implant intiyacı olan hastalar dahil edilmiştir. Hastalar dental volumetrik tomografi kullanılarak sinüs tabanı altında mevcut kemik yüksekliği ölçülerek $\geq 5 \mathrm{~mm}$ (Kontrol grubu) ve $<5 \mathrm{~mm}$ (Test grubu) olmak üzere iki gruba ayrılmıştır. Yerleştirilen implantların takip süresince sağkalım oranları değerlendirilmiştir.

Bulgular: Çalışmada toplam 31 hastaya yerleştirilen $62 \mathrm{imp}$ lant (Kontrol: 35, Test: 27) değerlendirilmiştir. Çalışmaya dahil edilen her iki grup kıyaslandığında sağkalım oranları açısından istatistiksel olarak anlamlı bir fark olmadığı gözlemlenmiştir.

Sonuçlar: Çalışmada rezidüel kemik yüksekliğinin, sinüs tabanı yükseltme operasyonu ile aynı seansta yerleştirilen dental implantların sağkalımını etkilemediği sonucuna varılmıştır.

Anahtar kelimeler: Dental implant, sağkalım oranı, tek aşama sinüs tabanı yükseltme

\section{SUMMARY}

Aim: Resorption occurs after teeth loss in alveolar ridge. In case of insufficient bone height in posterior maxilla, sinus floor operation for implant placement has been successfully applied for many years. The purpose of this study is to assess the success of implants placed simultaneously with sinus floor elevation operation, in cases where bone height under the sinus floor in the posterior maxilla is insufficient for implant placement.

Materials and Methods: In this retrospective study design, patients who were systemically healthy and required dental implant in posterior maxilla were included. Patients were divided into two groups; $\geq 5 \mathrm{~mm}$ (control group) and $<5 \mathrm{~mm}$ (test group) by measuring the bone height under sinus floor using dental volumetric tomography. Survival rates of implants were evaluated during follow-up.

Results: In this study, 62 implants placed in 31 patients (Control: 35, Test: 27) were evaluated. When the two groups included in the study were compared, it was observed that there was no statistically significant difference in survival rates.

Conclusions: The study concluded that the residual bone height did not affect the survival rate of dental implants placed simultaneously with the sinus floor elevation operation.

Keywords: Dental implant, survival rate, one stage sinus floor elevation 


\section{Giriş}

Modern diş hekimliğinde diş eksikliğinin rehabilitasyonunda dental implantlar en çok kullanılan yöntemlerden biridir. Dental implantların yerleştirilebilmesi için yeterli hacimde kemik dokusuna intiyaç vardır. Konvansiyonel tedavi protokolünde dental implantlar yerleştirildikten sonra 3 ile 6 aylık iyileşme süresinin ardından protetik safhaya geçilmektedir. ${ }^{1}$ Kemik yetersizliği durumunda implantlar yerleştirilmeden önce, çeşitli ogmentasyon yöntemleri uygulanarak kemik hacmi arttırılabilmektedir. Kullanılan biyomateryallere ve uygulanan tekniğe göre ogmentasyon işlemi iyileşme süresini 2-12 ay uzatabilmektedir. ${ }^{2}$ Dental implantların iyileşme süresinin kısaltılması için birçok teknik ve materyal geliştirilmektedir. ${ }^{3-5}$

İmplant destekli restorasyonların yapılabilmesi için, posterior maksillada yetersiz vertikal kemik yüksekliğinin rehabilitasyonunda en yaygın kullanılan yöntem sinüs tabanı yükseltme operasyonudur. Bu yöntem sinüs tabanı altında kalan rezidüel kemik miktarına bağlı olarak tek aşama veya iki aşama olarak uygulanmaktadır. Geçmişte yapılan çalışmalar, sinüs tabanı yükseltme operasyonunda greftleme prosedürü ve implantların aynı seansta yerleştirilmesi (tek aşama) için rezidüel kemik yüksekliğinin en az 4-5 mm olması gerektiğini göstermektedir.5-13 Günümüzde kullanılan implantların makro dizaynları ve mikro yüzeylerinde yapılan gelişmeler ışığında, rezidüel vertikal kemik yüksekliğinin minimal olduğu durumlarda sinüs tabanı yükseltme operasyonu sonrası çift aşama iyileşme yapılmadan uygulanan implantların hekim ve hasta açısından birçok avantajı olabilir. Tek aşama yerleştirilen implantlar total tedavi süresini, hasta morbiditesini, operasyon maliyetlerini azaltabileceği gibi hastaların tedaviyi onaylamalarını daha kolaylaştırabilir. Sinüs tabanı altındaki rezidüel kemik yüksekliği, yerleştirilen implantların başarısını etkileyerek klinisyenin tedavi seçiminde rol oynayabilir. Literatürde farklı kemik yüksekliklerinde sinüs operasyonuyla birlikte yerleştirilen implantların sağkalım başarısını değerlendiren çalışma sayısı az bulunmaktadır.

Bu çalışmanın amacı farklı rezidüel kemik yüksekliklerinde sinüs tabanı kaldırma operasyonu ile eş zamanlı yerleştirilen implantların sağkalım oranlarını değerlendirmektir. Çalışmada primer belirleyici değişken kemik yüksekliği, primer değerlendirilen sonuç ise implant sağkalım oranıdır. Çalışmanın hipotezi rezidüel kemik yüksekliğinin artışının implant sağkalım oranını pozitif yönde etkileyeceği yönünde kurgulanmıştır.

\section{GEREC VE YÖNTEM}

Bu retrospektif planlanan çalışmaya ekim 2014 ve aralık 2015 tarihlerinde İstanbul Aydın Üniversitesi Diş Hekimliği Fakültesi'ne dişsizlik şikayeti ile başvurmuş ve sinüs tabanı yükseltme operasyonu ile birlikte dental implant yerleştirilmesi planlanan hastalar dahil edilmiştir.
Çalışmaya dahil edilme kriterleri: American Society of Anesthesiologists (ASA) sınıflamasına göre ASA-1 sınıfında olup sinüs tabanı yükseltme operasyonu ile birlikte tek aşama gerçekleştirilen operasyonlar, ameliyat sırasında sinüs membranında $\leq 4 \mathrm{~mm}$ perforasyonu olan, sigara içen ( $\leq 20$ adet günde) ve içmeyenler, operasyon öncesi dental volumetrik tomografisi (DVT) olan hastalar çalışmaya dahil edilmiştir.

Çalışmaya dahil edilen hastalar klinik ve radyografik olarak değerlendirildikten sonra implant yerleştirilecek bölgeler belirlenmiş ve sinüs tabanı altında kalan rezidüel kemik yüksekliği DVT (Morita 3D Accuitomo 170 Dental, Japan) kullanılarak ölçülmüş ve kaydedilmiştir. Rezidüel kemik yüksekliği $\geq 5 \mathrm{~mm}$ olan hastalar kontrol grubu, $<5$ olan hastalar ise test grubu olarak dahil edilmiştir. Çalışmada yerleştirilen her implant ayrı değerlendirilmiştir (Re$\operatorname{sim} 1 a-d, 2 a-d)$.
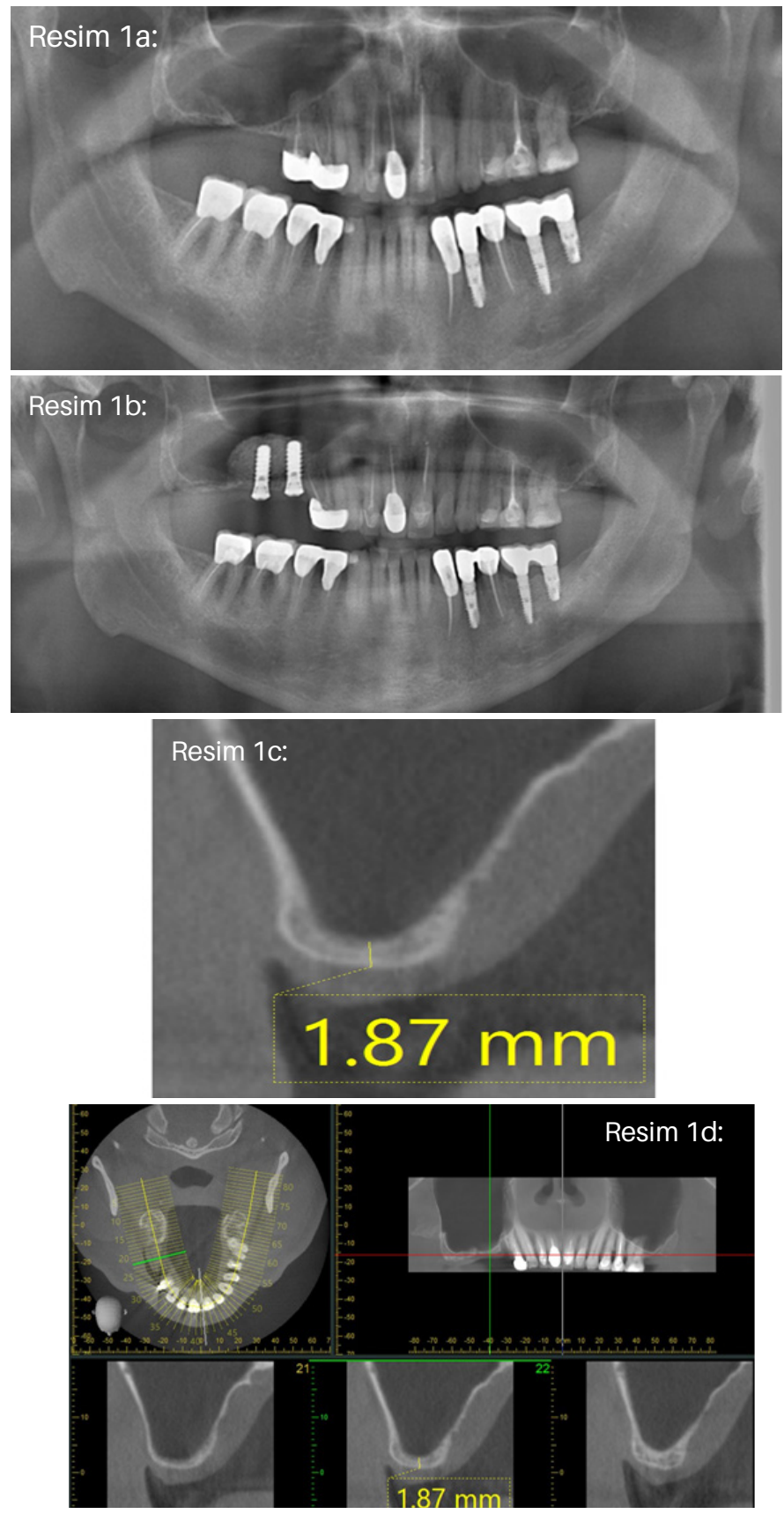

Resim 1a-d:Dental volumetrik tomografide rezidüel kemik yüksekliği $<5 \mathrm{~mm}$ olan test grubuna ait radyografik görüntü. 

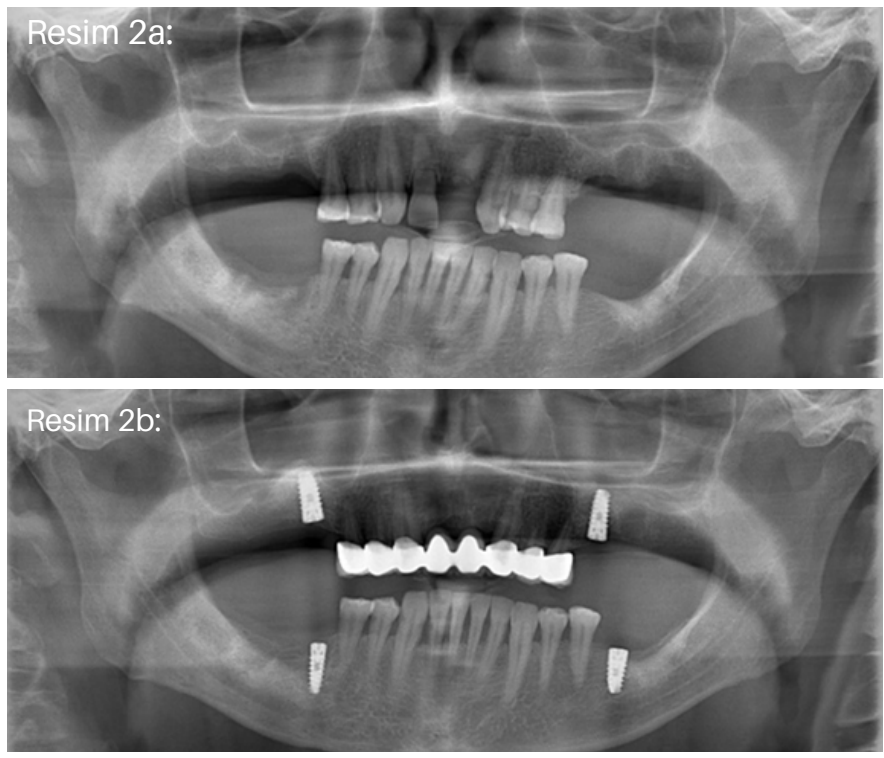

Resim 2c:
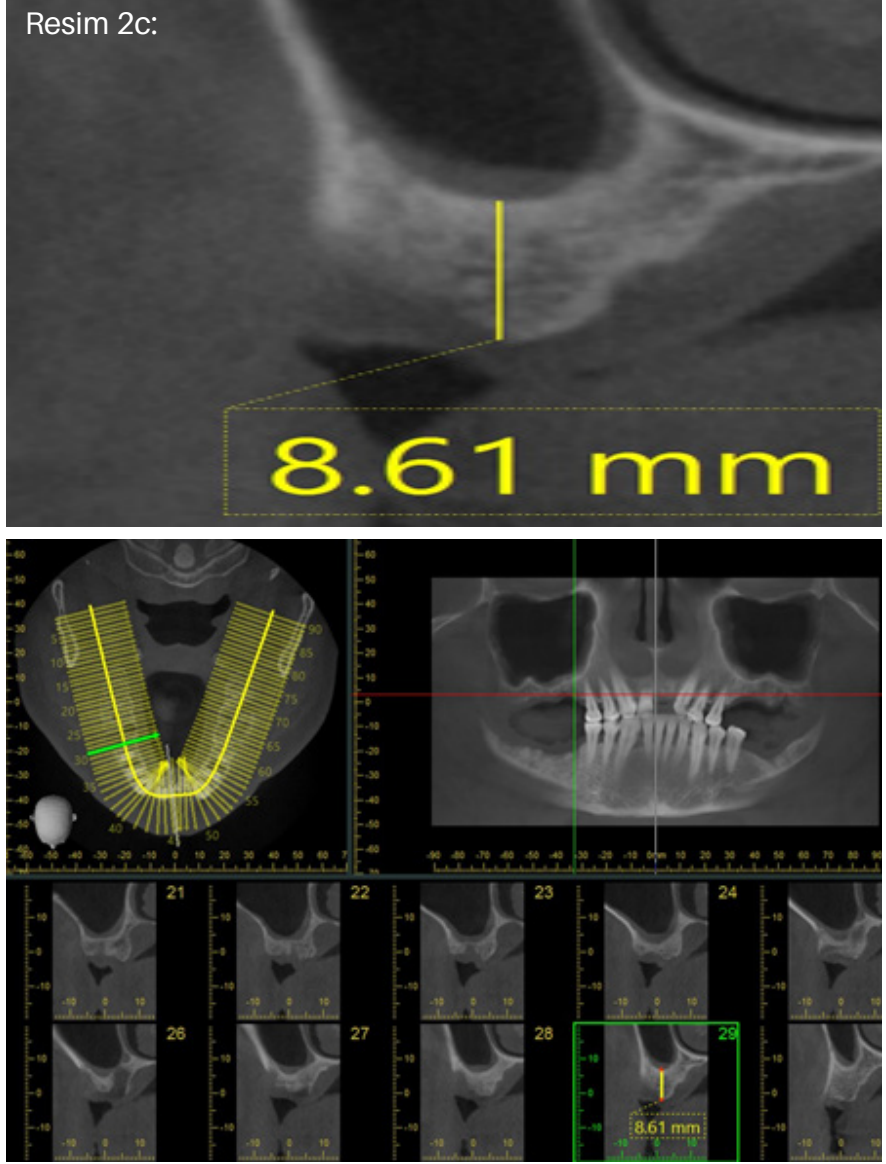

Resim 2a-d: Dental volumetrik tomografide rezidüel kemik yüksekliği $\geq 5 \mathrm{~mm}$ olan kontrol grubuna ait radyografik görüntü.

Çalışma kriterlerine göre uygun bulunan tüm hastalar İstanbul Aydın Üniversitesi Diş Hekimliği Fakültesi arşiv dosyalarından taranarak çalışmaya dahil edilmiştir. Bu çalışma protokolü Helsinki Deklerasyonu Prensipleri'ne uygun olarak İstanbul Aydın Üniversitesi Etik Kurulu tarafından 156 protokol no ile onaylanmıştır.

\section{Cerrahi Yöntem}

Çalışmaya dahil edilen tüm hastalara operasyon öncesi Klorheksidin gargara (Kloroben gargara, Drogsan, İstanbul, Türkiye) uygulanmıştır.

Lokal infiltratif anestezi (Ultracain DS forte, Articain, Aven- tis, Turkiye) sonrası 15 No'lu bistüri ile kret tepesinden insizyon yapılarak tam kalınlıkta flep kaldırıımıştır. Cerrahi olarak yeterli görüş alanı sağlanması için vertikal ve rahatlatıcı insiyonlarda uygulanmıştır. Daha kontrollü olması ve sinüs membranında perforasyon riskini azaltmak amacı ile 8 No'lu elmas rond frezlerle osteotomi gerçekleştirilmiştir. Maksiller sinüsün lateral duvarında pencere açılırken posterior superior alveolar arterin geçiş yolu dikkate alınarak pencere kret tepesinden yukarıda 5-16 mm aralığında hazırlanmıştır. Sinüs elevatörleri kullanılarak sinüs membranı eleve edilmiş ve implant kaviteleri hazırlanmıştır. Küçük perforasyonları onarmak ve işlem esnasında oluşabilecek perforasyonların önüne geçmek amacıyla greftleme prosedürüden önce sinüs membranının altına rezorbe olabilen kollajen membran (Tecnoss ${ }^{\circledR}$, Torino, italya) yerleştirilmiştir. Ardından maksiller sinüs kavitesin medial bölümü kortiko kansellöz xenograft (Tecnoss ${ }^{\circledR}$, Giaveno, İtalya) ile doldurulmuş ardından implantlar (Straumann, Waldenburg, İsviçre; Biohorizons, Alabama, Amerika; Medical Implant System, Shlomi, İsrail; İmplance, Trabzon, Türkiye) yerleştirilmiş ve daha sonra kalan boşluklara tekrar greft materyali yerleştirilmiştir. Greftleme prosedürünün ardından lateral pencere rezorbe olan kollajen membranla kapatılmış ve flep 4-0 trofilen sütur (Doğsan İstanbul, Türkiye) ile kapatılmıştır (Resim 3-5).

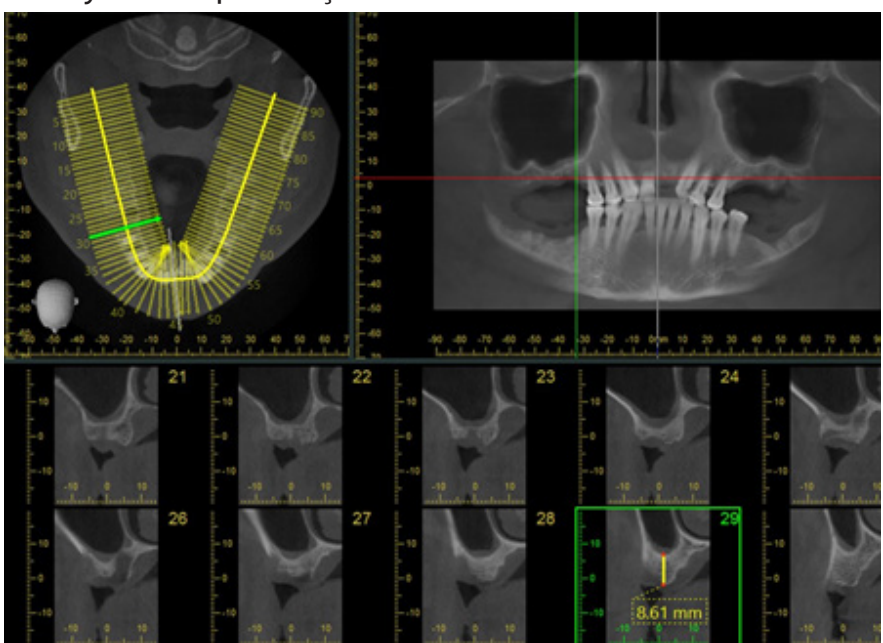

Resim 3: Maksiller sinüs ogmentasyonu için bukkal pencerenin açılması.

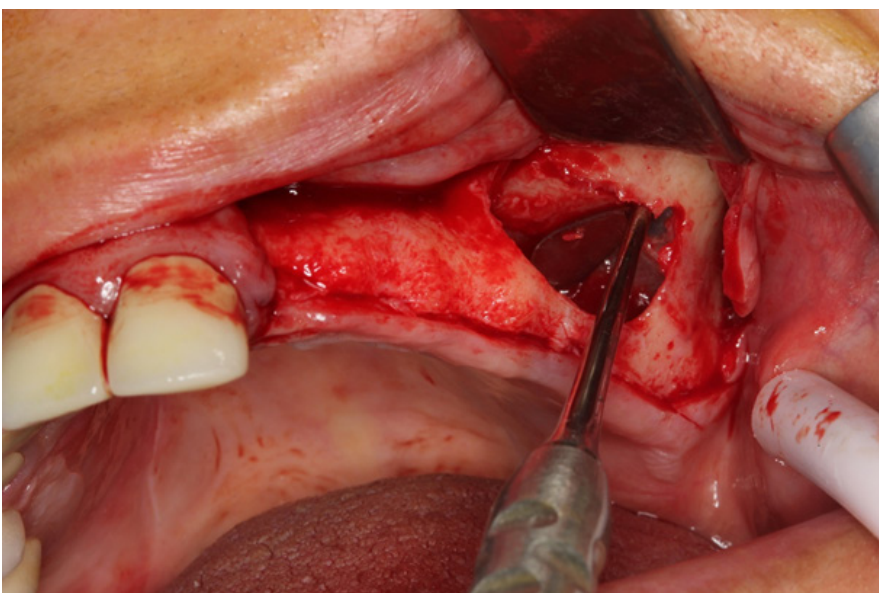

Resim 4: Sinüs membranının kaldırııması. 


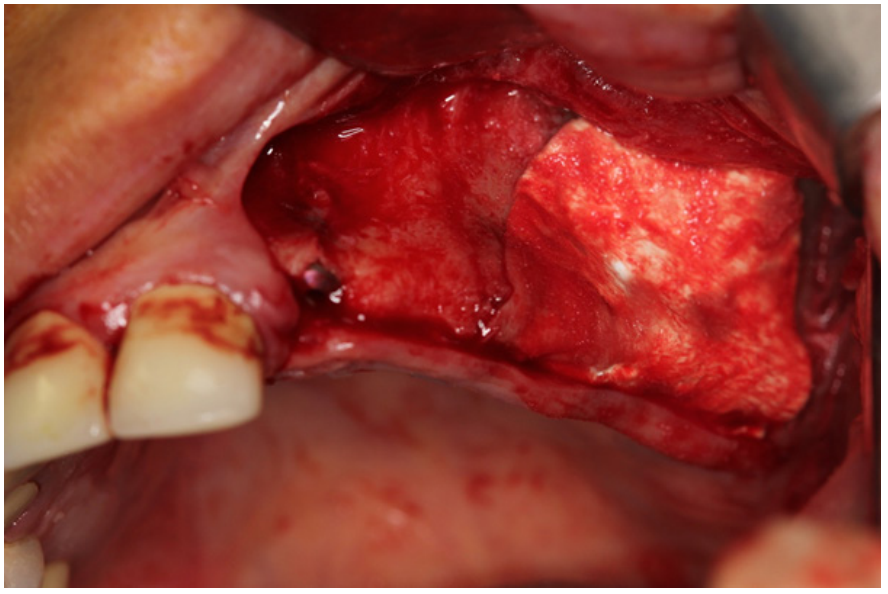

Resim 5: Biyomateryallerin uygulanması sonrasındaki görüntü.

Ameliyattan sonra hastalara oral yoldan 12 saat aralıkla 7 gün boyunca kullanması için Amoksisilin ve klavulanik asit (1 gr tablet); ağrı olunca analjezik (600 mg ibuprofen), ve ameliyattan sonra ertesi gün başlanmak üzere günde iki kez iki hafta boyunca \% 0.2 klorheksidin gargara reçete edilmiştir. Ameliyattan 10 gün sonra hastalar kontrole çağırıımış ve süturlar alınmıştır.

Operasyon sonrası 6 aylık iyileşme periyodunun ardından iyileşme başıkları takılmış ve protetik aşamaya geçilmiştir. İyileşme başıkları takıldığı seansta yerleştirilen implantlara torklu raşet anahtarı kullanılarak $25 \mathrm{~N}$ geri çevirme torku uygulanmış ve hareket etmeyen implantlar osteointegre olmuş kabul edilmiştir. Protetik tedavi bittikten sonra tüm hastalar 3, 6, 12, 18, 24 aylık rutin kontrollere çağrılmış, klinik ve radyografik olarak Albrekttson kriterlerine göre kontrol edilmiştir. ${ }^{3}$ Albrekttson kriterlerine göre radyografik değerlendirme rutin kontrollerde alınan panoramik radyografiler kullanılarak gözlemsel olarak yapılmış, implant etrafında yaygın radyolusent alan görülen implantlar başarısız kabul edilmiştir.

\section{İstatiksel İncelemeler}

Çalışmada elde edilen bulgular değerlendirilirken, istatistiksel analizler için IBM SPSS Statistics 22 (IBM SPSS, Türkiye) programı kullanılmıştır. Çalışma verileri değerlendirilirken parametrelerin normal dağılıma uygunluğu Shapiro Wilks testi ile değerlendirilmiştir. Çalışma verileri değerlendirilirken tanımlayıcı istatistiksel metodların (ortalama, standart sapma, frekans) yanısıra niceliksel verilerin karşılaştırılmasında normal dağılım gösteren parametrelerin iki grup arası karşılaştırmalarında Student $t$ test kullanılmıştır. Niteliksel verilerin karşılaştırılmasında ise Fisher Exact test, Fisher Freeman Halton Test ve Continuity (Yates) Düzeltmesi kullanılmıştır. Sağkalım analizi için Kaplan Meier Analizi kullanılmıştır. Anlamlılık $p<0.05$ düzeyinde değerlendirilmiştir.

\section{BULGULAR}

Çalışma yaşları 30 ile 73 arasında değişmekte olan 17'si $(\% 54,8)$ erkek ve 14 'ü $(\% 45,2)$ kadın olmak üzere toplam
31 hastanın 62 implantı üzerinde yapılmıştır. Olguların

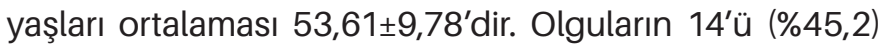
sigara kullanırken, 17'si (\%54,8) kullanmamaktadır (Tablo 1).

Tablo 1: Gruplar arasında tanımlayıcı özelliklerin değerlendirilmesi.

\begin{tabular}{|c|c|c|c|c|}
\hline & & \multicolumn{2}{|l|}{ Grup } & \multirow{2}{*}{$\mathbf{p}$} \\
\hline & & $\geq 5 \mathrm{~mm}(\mathrm{n}=35)$ & $<5 \mathrm{~mm}(\mathrm{n}=27)$ & \\
\hline Yaș ort $\pm S S$ & & $53,54 \pm 9,99$ & $56,22 \pm 8,05$ & 10,260 \\
\hline \multirow{2}{*}{ Cinsiyet $n(\%)$} & Erkek & $20(\% 57,1)$ & $16(\% 59,3)$ & \multirow{2}{*}{21,000} \\
\hline & \begin{tabular}{|l|} 
Kadın \\
\end{tabular} & $15(\% 42,9)$ & $11(\% 40,7)$ & \\
\hline \multirow{2}{*}{ Sigara $n(\%)$} & İçiyor & $11(\% 31,4)$ & $19(\% 70,4)$ & \multirow{2}{*}{${ }^{2} 0,005^{*}$} \\
\hline & İçmiyor & $24(\% 68,6)$ & $8(\% 29,6)$ & \\
\hline
\end{tabular}

Gruplar arasında yaş ortalamaları açısından istatistiksel olarak anlamlı bir farklılık bulunmamaktadır $(p>0,05)$.

Gruplar arasında cinsiyet dağılım oranları açısından istatistiksel olarak anlamlı bir farklılık bulunmamaktadır $(p>0,05)$.

Kemik yüksekliği $5 \mathrm{~mm}$ altında olanların sigara içme oranı $(\% 70,4), 5 \mathrm{~mm}$ üstünde olanların oranından $(\% 31,4)$ istatistiksel olarak anlamlı düzeyde yüksek bulunmuştur ( $p: 0,005 ; p<0,05)$.

Gruplar arasında ameliyat üzerinden geçen süre ortalamaları açısından istatistiksel olarak anlamlı bir farklılık bulunmamaktadır ( $p>0,05)$ (Tablo 2).

Tablo 2: Gruplar arasında çalışma parametrelerinin değerlendirilmesi.

\begin{tabular}{|c|c|c|c|c|}
\hline & & \multicolumn{2}{|l|}{ Grup } & \multirow[b]{2}{*}{$\mathbf{p}$} \\
\hline & & $\geq 5 \mathrm{~mm}$ & $<5 \mathrm{~mm}$ & \\
\hline \multicolumn{2}{|c|}{ Ameliyat üzerinden geçen süre (ay) $o_{r t \pm S S}$} & $15,10 \pm 4,43$ & $17,38 \pm 6,28$ & 10,116 \\
\hline \multicolumn{2}{|c|}{ Kemik Yüksekliği $o_{r t \pm S S}$} & $6,77 \pm 1,03$ & $3,43 \pm 1,09$ & $10,001 *$ \\
\hline \multirow{4}{*}{ İmp. Markası $n(\%)$} & Bio-Horizons & $5(\% 14,3)$ & $4(\% 14,8)$ & \multirow{4}{*}{20,496} \\
\hline & İmplance & $4(\% 11,4)$ & $1(\% 3,7)$ & \\
\hline & Mís & $16(\% 45,7)$ & $17(\% 63)$ & \\
\hline & Straumann & $10(\% 28,6)$ & $5(\% 18,5)$ & \\
\hline \multirow{2}{*}{$\operatorname{KAYIP}_{n}(\%)$} & Var & $3(\% 8,6)$ & $2(\% 7,4)$ & \multirow{2}{*}{31,000} \\
\hline & Yok & $32(\% 91,4)$ & $25(\% 92,6)$ & \\
\hline \multirow{2}{*}{$\begin{array}{l}\text { KAYIP Zamanı } n \\
(\%)\end{array}$} & Yükleme öncesi & $0(\% 0)$ & $2(\% 100)$ & \multirow{2}{*}{$\mathbf{3} 0,100$} \\
\hline & Yükleme sonrası & $3(\% 100)$ & $0(\% 0)$ & \\
\hline \multirow{2}{*}{ Perforasyon $n(\%)$} & Var & $1(\% 2,9)$ & $1(\% 3,7)$ & \multirow{2}{*}{31,000} \\
\hline & Yok & $34(\% 97,1)$ & $26(\% 96,3)$ & \\
\hline
\end{tabular}

Kemik yüksekliği $5 \mathrm{~mm}$ altında olanların kemik yüksekliği ortalaması, $5 \mathrm{~mm}$ üstünde olanların istatistiksel olarak anlamlı düzeyde düşük bulunmuştur ( $p: 0,001 ; p<0,05$ ).

Gruplar arasında imp. markası dağılım oranları açısından istatistiksel olarak anlamlı bir farklıık bulunmamaktadır ( $p>0,05)$.

Gruplar arasında kayıp olma durumu dağılım oranları açısından istatistiksel olarak anlamlı bir farklılık bulunmamaktadır ( $p>0,05)$.

Gruplar arasında kayıp zamanı dağılım oranları açısından istatistiksel olarak anlamlı bir farklıık bulunmamaktadır ( $p>0,05)$.

Gruplar arasında perforasyon varlığı dağıım oranları açısından istatistiksel olarak anlamlı bir farklılık bulunmamaktadır $(p>0,05)$.

\section{Sağkalım Analizi}

Toplam 62 implantın 5'inde (\% 8,1) kayıp görülmüştür. En son kayıp 16. ayda görülmüştür. Bu zaman içindeki 
sağkalım oranı $\% 90,5 \pm 4,3^{\prime}$ tür. Ortalama sağkalım süresi $23,35 \pm 0,69$ aydır.

Kemik yüksekliği $\geq 5 \mathrm{~mm}$ olan grupta 35 implantın 3'ünde (\%8.6) kayıp görülmüştür. En son kayıp 16. ayda görülmüş olup, bu zamandaki sağkalım oranı $\% 87.9 \pm 7.1$ 'dir. Ortalama sağkalım süresi $23.31 \pm 0.84$ aydır.

Kemik yüksekliği $<5 \mathrm{~mm}$ olan grupta 27 implantın 2'sinde (\%7.4) kayıp görülmüştür. En son kayıp 6.ayda görülmüş olup, bu zamandaki sağkalım oranı \%92.6 \pm 'tir. Ortalama sağkalım süresi 25.44 \pm 1.04 aydır.

Grup I ve Grup II'nin sağkalım oranları Log Rank test ile değerlendirildiğinde aralarında istatistiksel olarak anlamlı farklılık bulunmamıştır (Tablo 3).

Tablo 3: Grup I ve Grup II'nin sağkalım oranları, Log Rank.

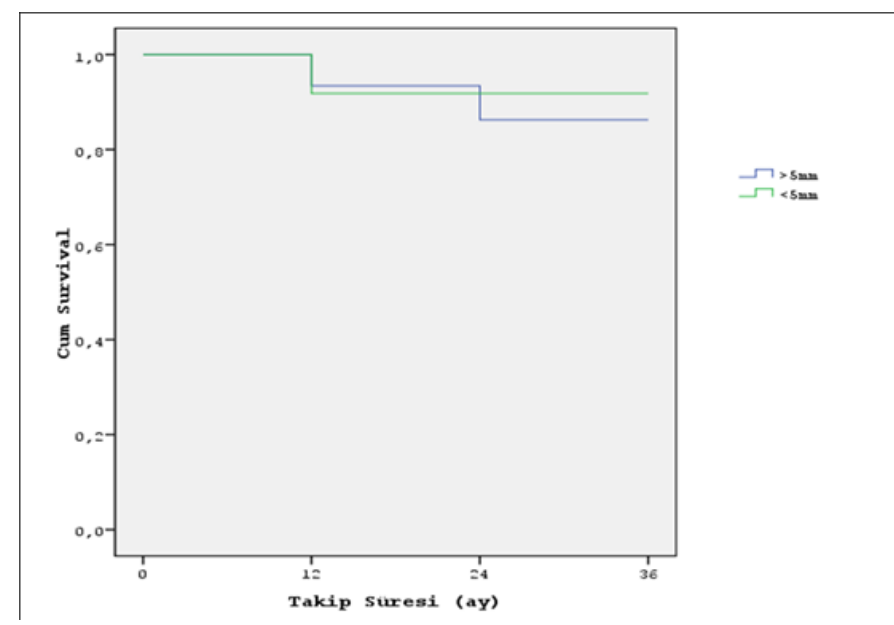

\section{TARTIŞMA}

Günümüz diş hekimliğinde kaybedilmiş dişlerin rehabilitasyonunda en sık kullanılan tedavilerden biri de dental implantlardır. Özellikle posterior maksillada dişlerin kaybedilmesi ile birlikte alveol kemiğinde rezorpsiyon ve maksiller sinüsün pneumatizasyonu kemik yüksekliğinde azalmaya neden olmaktadır. ${ }^{3}$ Posterior maksillada kemik yüksekliğinin ve hacminin arttırılmasında en çok tercih edilen yöntemlerden biride sinüs tabanı yükseltme operasyonudur. Çalışmamızda farklı rezidüel kemik yüksekliği gruplarında sinüs tabanı operasyonu ile eş zamanlı implant uygulamaları yapılmış ve her iki grupta benzer sağkalım oranları tespit edilmiştir. Çalışma öncesi kurgulanan hipotez red edilmiştir.

Literatürde yapılan çalışmalarda sinüs tabanı yükseltme operasyonu yapılarak uygulanan implantların 1 ile 9 yıllık takipler sonucundaki başarı oranının $\%>90$ olduğu bildirilmiştir. ${ }^{5-8,14-17}$ Bazı çalışmalarda rezidüel kemik yüksekliğinin $\leq 4 \mathrm{~mm}$ olduğu durumlarda aşamalı yaklaşımın daha güvenli olacağına vurgu yapılmıştır. ${ }^{5}$ Posterior maksillada rezidüel kemik miktarının yetersiz olduğu vakalarda $(\leq 4)$ greftleme prosedürü ve implantların aynı seansta yerleştirilmesinin güvenli yöntem olduğunu söyleyen çalışmalarda vardır. ${ }^{6-8,13}$ Fakat bu tür durumlarda sinüs tabanı kaldırma işlemi ile eş zamanlı implantasyon yapılan çalışmaların sayısı oldukça kısıtıdır. Felice ve ark. tek ve iki aşamalı si- nüs tabanı yükseltme operasyonu ile ilgili yaptıkları çalışmada, yerleştirilen implantlar arasında sağkalım oranlarını değerlendirilmiş ve istatistiksel olarak anlamlı bir fark gözlemlemediğini bildirmiştir. ${ }^{14}$ Bununla birlikte, bazı çalışmalarda sinüs tabanı altında 1 ila $3 \mathrm{~mm}$ kemik yüksekliğine sahip hastalarda, tek aşamalı sinüs tabanı yükseltme işlemi gerçekleştirilirken implant başarısızlık riski iki aşamalı cerrahiye oranla daha yüksek olabileceği vurgulanmıştır. ${ }^{18}$ Beretta ve ark. yaptıkları retrospektif çalışmada $15 \mathrm{yıl}-$ lık takip sonucunda tek aşamalı ve iki aşamalı sinüs tabanı yükseltme operasyonu ile yerleştirilen implantlar arasında sağkalım oranlarını değerlendirmiş ve iki yöntem arasında istatistik olarak fark olmadığını bildirmişlerdir. ${ }^{19,20}$ Zinser ve ark. yaptıkları çalışmada 347 sinüs tabanı yükseltme operasyonu ile yerleştirilen toplam 1047 implantta 14 yıllık takip sonunda sağkalım oranının \%93,3 olduğunu bildirmişlerdir. ${ }^{21}$ Literatürde tek ve çift aşama uygulanan sinüs tabanı kaldırma operasyonlarında tedavi başarısı bakımından farklı değerlendirmeler ve önermeler bulunmaktadır. Bizim çalışmamızda farklı rezidüel kemik yüksekliğinde uygulanan tek aşamalı implant uygulamalarında iki grup arasında bir fark tespit edilmemiştir. Bunun birkaç nedeni olabilir. Çalışmamızda kullanılan implantların büyük kısmının makro dizaynı konik ve implant yivleri belirgindir. Sadece Straumann marka implant silindir ve belirgin olmayan yivlere sahiptir. Bu implantta genel olarak kemik yüksekliği fazla olan hastalara yerleştirilmiştir. Yetersiz kemik varlığında primer stabilizasyonun sağlanmasında alıcı kemiğin miktarı, yoğunluğu, implantın makro dizaynı, cerrahi frezleme aşamaları, hekimin klinik tecrübesi gibi bir çok faktör rol oynamaktadır. ${ }^{22,23}$ Bu faktörlerden özellikle kullanılan implantın makro dizaynı, primer stabilizasyonun sağlanmasında klinisyenin başarısını etkilemektedir. ${ }^{24}$ Çalışmalarda konik ve agresif özellikli yivlere sahip implantların düşük kemik yoğunluğunda ve miktarında, silindir ve silik yivlere sahip implantlara göre yerleştirme torklarının daha yüksek olduğu belirtilmektedir. ${ }^{25-31}$ Yerleştirilen implantın iyileşme süresince stabilizasyonunun korunması, osseointegrasyonun sağlanması ve yükleme sonrasında korunmasında en önemli başarı faktörü olarak görülmektedir. ${ }^{32}$ İmplant sağkalım oranı bakımından gruplar arasında fark görülmemesinin diğer bir nedeni olarak da hasta seçim kriterleri gösterilebilir. Her ne kadar kemik yüksekliği az olan gruptaki $(<5 \mathrm{~mm})$ implantların sağkalımları değerlendirilse de, bu grupta ortalama kemik yüksekliğinin 3,5 mm olduğu görülmektedir. Dolayısıyla sadece 1-2 mm gibi kritik kemik yüksekliğindeki implant sağkalım oranlarının başarısı değerlendirilseydi, farklı sonuçlar alınabilirdi.

Pjetursson ve ark. ${ }^{30} 2008$ yılında yaptıkları 839 çalışma içeren ve rapor edilen sistematik meta-analiz çalışmasında sinüs tabanı yükseltme operasyonu uygulanan hastalarda implantların 3 yıllık sağkalım oranı \%90,1 olduğunu 
bildirmiştir. Bizim yaptığımız çalışmada da 31 hastada yerleştirilen toplam 62 implant için sağkalım oranı \%90,5 olduğu gözlemlenmiştir. Literatürde sinüs tabanı yükseltme operasyonu ile ilgili verilen sağkalım sonuçları bizim çalışma sonuçları ile benzerlik göstermektedir. Edinilen yüksek başarının sebebi olarak implant makro dizaynlarında ve yüzey özelliklerindeki gelişmeleri görmekteyiz. ${ }^{31-37}$

Sinüs tabanı yükseltme operasyonunda karşılaşılan intra-operatif komplikasyonlardan biri de sinüs membranında oluşan perforasyonlardır. Pikos yaptığı çalışmada sinüs tabanı yükseltme operasyonunda membran perforasyonunun görülme sıklığının \%19,5 olduğunu rapor etmiştir. ${ }^{20}$ Bizim çalışmamızda sinüs membran perforasyonu \%6,45 (toplam 31 hastanın ikisinde) olarak görülmüştür. Yapılan bazı çalışmalarda, sinüs tabanı yükseltme operasyonu sırasında oluşan sinüs membran perforasyonlarının, yerleştirilen implantların sağkalımını etkilemediğini bildirmişlerdir. ${ }^{19}$ Literatürde sinüs membranında oluşan perforasyonların başarıyı negatif yönde etkilediğini bildiren çalışmalar da var. ${ }^{38,39}$ Bizim çalışmamızda operasyon sırasında ortaya çıkan perforasyonlar kollajen membranla kapatılmış ve implantasyon işlemine devam edilmiştir. Perforasyon oluşan vakaların hiçbirinde implant kaybıyla karşılaşılmamıştır. Bu nedenle operasyon sırasında sinüs membranının bütünlüğünün bozulmasının, implantın osseointegrasyonunu etkilemediğini düşünmekteyiz.

Yapılan çalışmalar, cerrahi teknik olarak açılan sinüs penceresinin kollajen membranla örtülmesinin ogmentasyon başarısını arttırdığını bildirmektedir. ${ }^{31,32}$ Bizim çalışmamızda da standart protokol olarak, ogmentasyon bölgesine yumuşak doku hücrelerinin migrasyonunu engellemek amacıyla sinüs penceresi rezorbe olan kollajen membranla kapatılmıştır. Bu işlem her ne kadar tedavi masraflarını arttırsa da, kemik miktarının korunmasında yarar sağladığı için tüm hastalarda uygulanmıştır. ${ }^{31,32}$

Çalışmamızda implant başarısı üzerine değerlendirdiğimiz başka bir faktör de sigara kullanımıdır. Sigaranın implant başarısı üzerine negatif etkisi olduğunu rapor eden çalışmalar vardır. ${ }^{26}$ Bazı çalışmalarda sigara faktörü değerlendirilirken sigara kullanma süresi dikkate alınması gerektiğine vurgu yapılmıştır. ${ }^{33}$ Mundt ve ark. ${ }^{33}$ yaptıkları çalışmada, eskiden sigara kullananlar ve sigara kullanmaya devam edenler arasında implant başarısı açısından anlamlı bir fark olduğunu bildirmişlerdir. Bizim çalışmamızda sigaranın implant başarısı üzerine etkisi değerlendirildiğinde sigara kullanan ve kullanmayan gruplar arasında anlamlı bir fark bulunmamıştır. Ancak çalışmamızda hasta seçim kriterlerinde sigara içenler en fazla 20 adet ile sınırlandırılmıştır. Bunun nedeni günde 20'den fazla sigara kullanan hastalara protokol olarak bölümümüzde sert ve yumuşak doku ogmentasyon işlemleri uygulanmamaktadır. Çalışmamızın retrospektif olarak planlaması nedeniyle bu durum limitasyon olarak görülebilir. Sigara kullanımının fazla olduğu durumlarda, implant ile birlikte sinüs ogmentasyon işlemlerinin başarısı çalışma dizaynımız nedeniyle tam olarak değerlendirilemeyebilir. İleride prospektif yapılacak çalışmalarda, ülkemizde de oldukça fazla ileri düzey sigara kullanan hastaların başarısı objektif olarak değerlendirilebilir.

Conrad ve ark. ${ }^{31}$ yaptıkları çalışmada yaş faktörünün implant başarısı üzerine etkili olduğunu bildirmişlerdir. Yaş arttıkça kemik dokusunda bazı dejenerasyonların meydana geldiği ve bunun da implant başarısı üzerine etki ettiğini bildirmişlerdir. ${ }^{34-40}$ Çalışmamızda yaş ve cinsiyet faktörünün ogmentasyon işlemi ile birlikte uygulanan implant başarısı üzerine bir etkisinin olmadığı görülmüştür. Bunun nedeni olarak yapılan sinüs ogmentasyonlarının iyileşme kapasitesinin çok yüksek olması ve kullanılan implantlardaki teknolojik gelişmeler gösterilebilir. ${ }^{27}$ İmplant başarısını arttırmak için, implant dizaynı ve yüzey özelliklerinin geliştirilmesi konuları üzerine çok sayıda araştırma yapılmaktadır. Zinser ve ark. ${ }^{21}$ yaptıkları çalışmada sinüs tabanı yükseltme operasyonu uygulanan hastaların 14 yıllık takip sonucunda farklı implant sistemlerinin implant sağkalımı üzerine anlamlı bir etkisinin olmadığını bildirmişlerdir. Bizim çalışmamızda da birçok implant markası kullanılmıştır. Bias oluşturması nedeniyle, istatiksel olarak kullanılan markaların başarısını karşılaştırmak, implantların sayısının yeterli sayıda olmaması nedeniyle mümkün olmamıştır. Genel olarak, kullanılan tüm implantların başarılı olduğu söylenebilir. Ancak yüksek implant başarı oranı, lateral veya vertikal ogmentasyon gibi iyileşme kapasitesinin azaldığı durumlarda düşebilir.

Çalışmamızda bazı eksiklikler bulunmaktadır. Büyük oranda retrospektif çalışma dizaynı ile ilgili olan bu eksiklikler arasında en önemlisi çalışma takip süresinin beş yıldan az olması gösterilebilir. Her ne kadar ogmentasyon işlemleri sonrası görülen komplikasyonların en fazla ilk bir yıl içinde karşılaşıldığı gösterilse de, uzun dönem implant başarısının değerlendirilmesi, elde edilen sonuçların daha iyi yorumlanmasını sağlayabilir. ${ }^{27}$ Diğer bir eksiklik olarak, çalışmamızda yerleştirilen implantların yumuşak doku sağlığının değerlendirilmesinin yapılmaması gösterilebilir. Çalışmalarda özellikle implant çevresinin sondalanmasının, son derece zayıf bağlantısı olan yumuşak dokunun resessiyonuna sebep olsada, günümüzde sondalamanın peri-implanter sağlığın takibinde yaygın bir değerlendirme metodu olduğu bilinmektedir. ${ }^{29}$ Ancak peri-implanter dokunun sağlığı ile ilgili bir ölçüm yapılmamıştır.

\section{SONUCLAR}

Bu çalışmada eksikliklere rağmen, rezidüel kemik yüksekliği düşük olan hastalarda bile sinüs tabanı yükseltme operasyonu ile implantların eşzamanlı yapılmasının başarılı ve güvenle kullanılabilecek bir yöntem olduğu kanısına varılmıştır. Daha kesin sonuçlar için hasta sayısının art- 
tırılmasına ve daha uzun dönem takip sonuçlarına ihtiyaç vardır.

\section{KAYNAKLAR}

1. Gehrke SA, Tavares da Silva Neto U. Does the time of osseointegration in the maxilla and mandible differ? J Craniofac Surg 2014; 25: 2117-21120.

2. Kahnberg KE, Vannas-Löfqvist L. Sinus lift procedure using a 2-stage surgical technique: I. Clinical and radiographic report up to 5 years. Int $\mathrm{J}$ Oral Maxillofac Implants 2008; 23: 876-884.

3. Albrektsson T, Sennerby L, Wennerberg A. State of the art of oral implants. Periodontol 2000 2008; 47: 15-26.

4. Le Guehennec L et. al. Histomorphometric analysis of the osseointegration of four different implant surfaces in the femoral epiphyses of rabbits. Clin Oral Implants Res 2008; 19: 1103-1110.

5. Chiapasco M, Zaniboni M. Methods to treat the edentulous posterior maxilla: Implants with sinus grafting. J Oral Maxillofac Surg 2009; 67: 867-871.

6. Kahnberg KE, Vannas-Löfqvist L. Sinus lift procedure using a 2-stage surgical technique: I. Clinical and radiographic report up to 5 years. Int $\mathrm{J}$ Oral Maxillofac Implants 2008; 23: 876-884.

7. Raghoebar GM, Vissink A, Reintsema H, Batenburg RH. Bone grafting of the floor of the maxillary sinus for the placement of endosseous implants. Br J Oral Maxillofac Surg 1997; 35: 119-125.

8. Peleg M, Mazor Z, Chaushu G, Garg AK. Sinus floor augmentation with simultaneous implant placement in the severely atrophic maxilla. J Periodontol 1998; 69: $1397-$ 1403.

9. Jensen OT, Shulman LB, Block MS, lacono VJ. Report of the Sinus Consensus Conference of 1996. Int J Oral Maxillofac Implants 1998; 13: 11-45.

10. Tiwana PS, Kushner GM, Haug RH. Maxillary sinus augmentation. Dent Clin North Am 2006; 50: 409-424.

11. Chen TW, Chang HS, Leung KW, Lai YL, Kao SY. Implant placement immediately after the lateral approach of the trap door window procedure to create a maxillary sinus lift without bone grafting: A 2-year retrospective evaluation of 47 implants in 33 patients. J Oral Maxillofac Surg 2007; 65: 2324-2328.

12. Jurisic $M$, Markovic $A$, Radulovic $M$, Brkovic BM, Sándor GK. Maxillary sinus floor augmentation: Comparing osteotome with lateral window immediate and delayed implant placements. An interim report. Oral Surg Oral Med Oral Pathol Oral Radiol Endod 2008; 106: 820-827.

13. de Vicente JC, Hernández-Vallejo G, Braña-Abascal $P$, Peña I. Maxillary sinus augmentation with autologous bone harvested from the lateral maxillary wall combined with bovine-derived hydroxyapatite: Clinical and histologic observations. Clin Oral Implants Res 2010; 21: 430438.
14. Lambert F, Lecloux G, Rompen E. One-step approach for implant placement and subantral bone regeneration using bovine hydroxyapatite: A 2- to 6-year follow-up study. Int J Oral Maxillofac Implants 2010; 25: 598-606.

15. Fugazzotto PA, Vlassis J. Long-term success of sinus augmentation using various surgical approaches and grafting materials. Int J Oral Maxillofac Implants 1998; 13: 52-58.

16. Rodriguez $A$, Anastassov GE, Lee $H$, Buchbinder $D$, Wettan $\mathrm{H}$. Maxillary sinus augmentation with deproteinated bovine bone and platelet rich plasma with simultaneous insertion of endosseous implants. J Oral Maxillofac Surg 2003; 61: 157-163.

17. Peleg M, Garg AK, Mazor Z. Predictability of simultaneous implant placement in the severely atrophic posterior maxilla: A 9-year longitudinal experience study of 2132 implants placed into 731 human sinus grafts. Int $\mathrm{J}$ Oral Maxillofac Implants 2006; 21: 94-102.

18. Felice $P$, et.al. 1-stage versus 2 -stage lateral maxillary sinus lift procedures: 4-month post-loading results of a multicenter randomised controlled trial. Eur $\mathrm{J}$ Oral Implantol 2013; 6: 153-165.

19. Beretta M, Poli PP, Grossi GB, Pieroni S, Maiorana C. Long-term survival rate of implants placed in conjunction with 246 sinus floor elevation procedures: results of a 15 year retrospective study. J Dent 2015; 43: 78-86.

20. Pikos MA. Maxillary sinus membrane repair: update on technique for large and complete perforations. Implant Dent 2008; 17: 24-31

21. Zinser MJ, Randelzhofer $P$, Kuiper $L$, Zöller JE, De Lange GL. The predictors of implant failure after maxillary sinus floor augmentation and reconstruction: a retrospective study of 1045 consecutive implants. Oral Surg Oral Med Oral Pathol Oral Radiol 2013; 115: 571-582.

22.Yoon HG, Heo SJ, Koak JY, Kim SK, Lee SY. Effect of bone quality and implant surgical technique on implant stability quotient (ISQ) value. J Adv Prosthodont 2011; 3: 10-15

23.Coelho PG, Jimbo R, Tovar N, Bonfante EA. Osseointegration: hierarchical designing encompassing the macrometer, micrometer, and nanometer length scales. Dent Mater 2015; 31: 37-52.

24. Halldin A, et. al. The effect of static bone strain on implant stability and bone remodeling. Bone 2011; 49: 783789.

25.Trisi P, Berardini M, Falco A, Podaliri Vulpiani M. Effect of Implant Thread Geometry on Secondary Stability, Bone Density, and Bone-to-Implant Contact: A Biomechanical and Histological Analysis. Implant Dent 2015; 24: 384-391.

26.Ting M, Rice JG, Braid SM, Lee CYS, Suzuki JB. Maxillary Sinus Augmentation for Dental Implant Rehabilitation of the Edentulous Ridge: A Comprehensive Overview of 
Systematic Reviews. Implant Dent 2017; 26: 438-464.

27. Gultekin BA, et. al. Evaluation of Volumetric Changes of Augmented Maxillary Sinus With Different Bone Grafting Biomaterials. J Craniofac Surg 2016; 27: 144-148.

28. Thoma DS, Zeltner $M$, Hüsler J, Hämmerle $\mathrm{CH}$, Jung RE. EAO Supplement Working Group 4 - EAO CC 2015 Short implants versus sinus lifting with longer implants to restore the posterior maxilla: a systematic review. Clin Oral Implants Res 2015; 154-169.

29. Gultekin BA, Sirali A, Gultekin P, Yalcin S, Mijiritsky E. Does the Laser-Microtextured Short Implant Collar Design Reduce Marginal Bone Loss in Comparison with a Machined Collar? Biomed Res Int 2016; 2016:9695389.

30. Pjetursson BE, Tan WC, Zwahlen M, Lang NP. A systematic review of the success of sinus floor elevation and survival of implants inserted in combination with sinus floor elevation. J Clin Periodontol 2008; 35: 216-240.

31. Conrad HJ, Jung J, Barczak M, Basu S, Seong WJ. Retrospective cohort study of the predictors of implant failure in the posterior maxilla. Int $\mathrm{J}$ Oral Maxillofac Implants 2011; 26: 154-162.

32. Nkenke E, Stelzle F. Clinical outcomes of sinus floor augmentation for implant placement using autogenous bone or bone substitutes: a systematic review. Clin Oral Implants Res 2009; 4: 124-133.

33. Mundt T, Mack F, Schwahn C, Biffar R. Private practice results of screw-type tapered implants: survival and evaluation of risk factors. Int J Oral Maxillofac Implants 2006; 21: 607-614.

34. Seong WJ, et. al. Elastic properties and apparent density of human edentulous maxilla and mandible. Int $\mathrm{J}$ Oral Maxillofac Surg 2009; 38: 1088-1093.

35. Nasr S, Slot DE, Bahaa S, Dörfer CE, Fawzy El-Sayed $\mathrm{KM}$. Dental implants combined with sinus augmentation: What is the merit of bone grafting? A systematic review. J Craniomaxillofac Surg 2016; 44: 1607-1617.

36. Aguirre Zorzano LA, Rodríguez Tojo MJ, Aguirre Urizar JM. Maxillary sinus lift with intraoral autologous bone and B - Tricalcium phosphate: Histological and histomorphometric clinical study. Med Oral Patol Oral Cir Bucal 2007; 12: 532-536.

37. Lee BK. One-stage operation of large oroantral fistula closure, sinus lifting, and autogenous bone grafting for dental implant installation. Oral Surg Oral Med Oral Pathol Oral Radiol Endod 2008; 105: 707-713.

38. Proussaefs P, Lozada J, Kim J, Rohrer MD. Repair of the perforated sinus membrane with a resorbable collagen membrane: a human study. International Journal of Oral \& Maxillofacial Implants 2004; 19: 413-420.

39. Khoury F. Augmentation of the sinus floor with mandibular bone block and simultaneous implantation: a 6-year clinical investigation. International Journal of Oral \& Maxillofacial Implants 1999; 14: 557-564.
40. Illker Keskiner, Ahmet Aydoğdu, Ayça Ersoy Kaleli, Mahmut Sümer. The comparison of oral temperature measurements in smokers and non-smokers. Yeditepe JDent 2015; 11: 5-10. 